\title{
How bartenders relate to intoxicated customers
}

\author{
Kristin Buvik \\ Norwegian Institute for Alcohol and Drug Research (SIRUS), Oslo, Norway
}

\begin{abstract}
Aims: In many studies, the extent of over-serving has been registered, but few attempts have been made to understand what happens in these situations when alcohol is ordered. The present study was designed to address two questions: How can we understand and explain why bartenders over-serve customers who are clearly intoxicated? What influences the interactions between bartenders and customers in situations in which alcohol is served?

Design: Observation of 32 purchase attempts with pseudo-patrons, and in-depth interviews with seven bartenders. The bartenders interviewed were not those who were involved in the test purchasing.

Findings: In the majority of cases, the pseudo-patrons were served without the bartender showing any sign of evaluating the customer's level of intoxication. Three factors affect the bartenders' interactions with intoxicated customers: a working situation not adapted for responsible serving; a drinking culture with a collective acceptance of intoxication; and opposition to the Alcohol Act, which is seen as too strict and ineptly enforced. Bartenders blamed their serving of intoxicated patrons on hectic working conditions as well as on wanting to maintain a good atmosphere in the bar and avoid conflicts. Observation at the premises showed a liberal drinking culture that legitimizes a high level of intoxication.
\end{abstract}

Conclusions: As long as the customer appears pleasant and not confrontational, they can have another beer. Serving is the rule, and denial of service is the exception.

The Norwegian drinking pattern is characterized by drinking on weekends and at parties, often without food, and often to excess (Horverak \& Bye, 2007, p. 201). Premises where alcohol is served are arenas for intoxication (Lund, 2007; Nordlund, 1990; Rossow \& Træen, 1995), and it is not unusual to see people who are drunk in these places on weekends (Nordlund \& Østhus, 2012). The Norwegian Alcohol Act was framed from a public health perspective and aims to limit the damage caused by use of alcohol. It forbids the serving of alcohol to people who are clearly under the influence of alcohol. The act requires that control authorities ensure that the law is enforced, with undercover inspectors regularly visiting venues to check compliance with the law.

Test buying is commonly used to study over-serving. Pseudo-patrons simulate intoxication when ordering alcohol in bars, and the server's response is recorded. Several test buying studies in Norway have shown that bartenders serve customers who are clearly intoxicated (Buvik \& Baklien, 2006; Holth \& Bye, 2004; Lauritzen \& Baklien, 2007; Rossow \& Baklien, 2010). A study in Oslo, Norway in October 2011 included 89 test buys in 30 premises. The pseudo-patrons were served in 93\% of cases. Most bartenders served alcohol without appearing to assess customers' level of intoxication, and interaction between bartenders and customers was limited (Buvik \& Baklien, 2012). International studies report similar results (Andreasson, Lindewald, \& Rehnman, 2000; Freisthler, Grunenwald, Treno, \& Lee, 2003; Lang, Stockwell, Rydon, \& Beel, 1998; Rydon, Stockwell, Lang, \& Beel, 1996; Toomey et al., 2008; Toomey et al., 2004; Toomey et al., 1999; Warpenius, Holmila, \& Mustonen, 2010).

Previous studies have measured the extent of over-serving, but there have been few attempts to study the interaction between customers and bartenders, or to include the bartenders' perspective (McKnight, 1991; Rydon et al., 1996; Saltz, 1989; Stockwell, 1992; Toomey et al., 1999). To understand the high level of over-serving, we need qualitative and descriptive studies that include the bartenders' perspective (Graham, 2008; Toomey et al., 2008). The research question in this study is: why do bartenders serve customers who are clearly intoxicated?

\section{Methods}

This article is based on observation at bars and nightclubs in central Oslo and qualitative interviews with bartenders. 
The observations were part of an evaluation of a prevention program aimed at premises in an area of the city center in Oslo (Oslo kommune, 2012). Four pseudo-patrons conducted 89 test purchases on two Fridays and Saturdays in October 2011 at all bars and nightclubs in this area and a control area. Only venues without table service were selected (Buvik \& Baklien, 2012). To enable observers to obtain good ethnographic descriptions of the social environment at the venues, we spent more time at each venue than the pseudo-patrons; therefore, we observed approximately every third purchase attempt, making 32 observations in total. The main focus was the interaction between the bartender and the pseudo-patron.

Observations took place in 24 different premises. We visited most venues once, but one randomly selected venue received two visits. There are only a few nightclubs in these areas, so 25 of the 32 observations were at bars or pubs, with seven observations at nightclubs. We made 20 observations between 11 p.m. and 1 a.m., and 11 observations between 1 a.m. and 3 a.m. Two pseudopatrons were used for each purchase; male-male pairs made 10 purchase attempts, female-female pairs six attempts and male-female pairs 16 attempts. They used the same scripted and practiced act at all venues, but the act was adapted to the context.

Different observation methods are reported in the literature, with some studies using one observer (Rydon et al., 1996; Toomey et al., 2004; Warpenius et al., 2010) and others two (Gliksman et al., 1993; Wallin, Gripenberg, \& Andreasson, 2005). We chose two observers because people usually go to bars in the company of others, and we assumed observers would attract more attention if they appeared alone. Two observers can also provide more detail than one, and it was useful for the observers to discuss events with each other.

The actors filled out a record for each purchase attempt, based on a schedule developed by Graham, Bernards, Osgood, and Wells (2006) and later used in European studies by Hughes et al. (2012). The form comprises questions designed to measure aspects of the bar environment, including: door staff, queue outside the premises, queue at the bar, crowding, intoxication levels of guests, noise (music), lighting, and cleanliness. The bartender's sex and approximate age were recorded, together with his or her response to the pseudo-patron, specifically: service refused, hesitation, offer of a nonalcoholic drink, call for bouncer, and pressure to drink (before the pseudo-patron had managed to place the order). In addition, researchers interviewed the actors afterward and compared their records with notes from observations. This helped in creating a shared understanding of situations.

The observers arrived at the bar before the pseudo-patrons; they ordered beer and stood by the counter until the purchase attempt was completed. There was usually a distance of about one meter or less between the observers and the pseudo-patrons. This generally allowed observers to see facial expressions and to hear the conversation between the bartender and the pseudo-patron. Occasionally, loud music made the conversation inaudible, and for five observations the bar was crowded and facial expressions were more difficult to observe. Each observation lasted between 15 and 90 minutes, with an average of about 30 minutes. Observers made notes on cell phones inside the premises and in notebooks in the restrooms, and wrote more complete field notes the next morning.

During observations, the research team became increasingly interested in the perspective of the bartenders and wanted to include their experiences and opinions to get a fuller picture of over-serving. As Patton (1990) notes, " $[\mathrm{W}] \mathrm{e}$ interview people to find out from them those things we cannot directly observe, because we cannot observe feelings, thoughts and intentions” (Patton, 1990, p. 278).

An interview guide was developed from a pilot interview with a bartender. To maintain anonymity, we did not approach bartenders involved in the test buying that had been observed, but recruited interviewees through social networks and snowball sampling. Research participants were paid 300 NOK (about US\$ 50).

We interviewed one female and six male bartenders aged 25-35 years. They worked in bars and nightclubs similar to those used for the test buying and observations. The interviews took place in an office in the center of Oslo. They lasted between 60 and 90 minutes and were recorded and transcribed. Interviews followed a semi-structured guide, with the main topics being training, guests' intoxication levels, refusing guests, allocation of responsibilities, the Alcohol Act, supervising authorities, bartenders' own alcohol consumption, and industry affiliation. In addition, interviewers presented results from the purchase attempts and discussed interpretations of these events with interviewees.

Our analysis of the interviews and notes from fieldwork began with the coding of themes broadly pertaining to possible explanations for serving intoxicated guests. After this initial coding, statements and fieldwork notes consistent with the three themes that make up the results of the current analysis were systematically coded. This style of coding is consistent with grounded theory (Corbin \& Strauss, 2008) and general standards of qualitative research techniques (Kvale \& Brinkmann, 2009; Silverman, 2010).

\section{Results}

Of the 32 observed test purchases, 29 ended with service. Most bartenders served alcohol without appearing to assess the customers' level of intoxication. One bartender encouraged the pseudo-patron to purchase alcohol even before he had time to order a beer. Two bartenders were apparently reluctant, but served guests anyway. Three purchase attempts ended with refusal. In one, the pseudopatron was offered a glass of water and in another, the bartender called security staff to evict the pseudo-patron. 
Observations and interviews suggest three main reasons for over-serving: bartenders' working conditions, a general culture of drunkenness, and (as an extension of this) skepticism about the Alcohol Act.

\section{Bartenders' Working Conditions}

Venues were crowded at five of the 32 observations, and the intoxication level among guests was categorized as "high" in 10 observations. There was loud music at 18 observed events and dim lighting in 12 . Observers noted on several occasions that the bartender's ability to assess customers was limited:

It is Saturday night, and 10 minutes before closing time. The place is small and crowded. The music is loud. It looks as though people are about to have sex on the dance floor. Three men are behind the bar and many customers are waiting to be served. The pseudopatrons come in and spend time getting to the bar. One staggers and her knees give way as she gets to the bar. She leans on the counter and waves her arms to get attention. The bartender does not look at her, and it is impossible for him to hear what she is saying. She rocks from side to side and she does not manage to focus her gaze. She leans over to the bartender and shouts that she wants a beer. He does not look at her, just gives her a beer.

Although there were crowds and loud music in many premises, in other premises, bartenders often had good opportunities to assess customers, yet they served the pseudo-patrons even when there were no other customers in the bar, the music was low and the lighting was good.

It is 11 o'clock on Saturday evening. There are few customers in the premises. The music is low, the customers are not very intoxicated and the lighting is good. A young woman is working in the bar. There are no customers in the bar. The pseudo-patron stumbles through the door. He walks unsteadily to the bar and asks with a slurred voice what a beer costs. The bartender does not understand what he says. He repeats three times that he wants a beer. When she begins to serve him, a male bartender comes into the bar. He looks at the pseudo-patron, but he just walks past. The female bartender gives him a beer.

We observed several instances of over-serving in quiet conditions, but none of the interviewees reported this (perhaps for good reasons). This highlights the importance of using mixed methods to get a fuller picture. Bartenders explain over-serving as a response to difficult working conditions, characterized by stress and pressure. They report that it is not easy to judge a customer's intoxication level when there are many customers and a lot of noise: "There are five customers ordering at the same time that we are trying to attend to, three to five people all the time. We don't manage to have a conversation with one person" (Tim, 28). The actual ordering of drinks often happens very quickly: "The seconds at the bar-it is really difficult. ... And we don't talk to each other. Often we don't even hear what people say. They indicate what they want with their fingers. 'Two beers.' 'OK, two beers.' And then they leave the bar" (Chris, 28). In addition, there is pressure from supervisors and bosses: "It's part of the job that everything must happen quickly. If you don't manage to work quickly enough, then you don't have a job” (Chris). In sum, bartenders typically mention hectic working conditions and a high turnover as reasons for over-serving. They also talk about the expectations of bosses and customers, and the risk of losing one's job if these are not met. Bartenders' working conditions, characterized by stress and pressure, are one way of understanding overserving. At the same time, the observation data show that over-serving happens all the time, even in quiet conditions.

\section{A Culture of Drunkenness}

Observations at premises where alcohol is served show a liberal drinking culture that legitimizes a high level of intoxication. Our observations reveal that there is a high level of over-serving in many places:

People are crowding just inside the door. There is a high level of intoxication; people shout and wave. Behind us, a man nearly falls off his bar stool several times. Another man is so unsteady that he can hardly stand. He is leaning against the wall. The atmosphere is unpleasant, people move around in an aggressive way.

During our observations, we saw many guests who were as drunk as the pseudo-patrons appeared to be. The case report below is from a Saturday evening at a small pub, about half an hour before closing time:

There is a young man behind the counter. Two girls are ordering vodka shots. They ask the bartender to take pictures of them while they shoot the vodka. They giggle and are quite loud. One of the girls staggers and holds onto the bar. It looks as if she is trying to pull herself together; she looks at the bartender in a slightly apologetic manner. A guy comes in the door, with a bouncer running after him. He is obviously drunk-he staggers and screams while the bouncer throws him out. Some young people are sitting by a table in a corner. They shout and scream and laugh a lot. One of them is laughing so much that he falls off his chair. He is lying on the floor for a few seconds before his buddy helps him up. He looks very unstable.

Bartenders confirm our impression from observations, and they talk about widespread drunkenness, a typical statement being: "But at the weekends, of course everyone is drunk" (Anthony, 29). Bartenders emphasize that it is important to maintain a good atmosphere at the venue because they want their guests to have fun. The interviews show that bartenders try to avoid confrontations. They report that customers they refuse to serve can threaten them and become very angry: "There is nothing that makes people angrier than if you refuse to serve them. I have been called 'tart,' 'cunt' and 'old bag"' (Anna, 35). Another bartender says: "It's not easy to deal with drunken customers. I have experienced threats many times" (Blix, 26). The bartenders want to provide good service and they want 
guests to be happy: "It can be much easier to give people one beer too many than to ask them to go home. This may be one reason why there is less refusal [of service] late at night, when the bartender is tired and cannot bear any more bickering" (Anna).

Bartenders say that serving customers provides a more predictable outcome than refusing to serve them. The interviews show that when bartenders assess customers, they see not only the inebriation but also the customers' behavior more generally. If the customer is happy and pleasant, but drunk, it is typically not seen as a problem to give him or her another beer.

Bartenders confirm that high alcohol consumption occurs not only among the guests but also among the employees. They say that they get cheaper beer at their workplaces and that it is not unusual for them to visit the workplace as guests. Bartenders say their job is part of a lifestyle that involves a lot of partying. One bartender comments: "It's different than a regular job, you are organizing a party, in a way. Together. Each weekend. And you have fun together and we often go out on Sundays together and have some beers” (Anthony).

The serving of alcohol at clubs and bars takes place within a drinking culture that values high levels of intoxication. Bartenders are surrounded by people who drink a lot of alcohol, and they are themselves part of the same drinking culture. This affects their relative view of drunkenness and they are generally accepting of heavy drinking. This culture of drunkenness makes over-serving of intoxicated guests more common. In the eyes of the bartenders, it may not even qualify as over-serving; it is not obvious that the supervising authorities and bartenders agree on when a guest is intoxicated. Moreover, their main emphasis is on keeping customers happy and maintaining a good atmosphere. Refusing to serve may potentially create conflicts.

\section{Skepticism about the Alcohol Act}

The two reasons for over-serving mentioned above were based on observations that were later confirmed in interviews. This final aspect of over-serving, however, only appeared in interviews and demonstrated again the importance of using several forms of qualitative data. In interviews, bartenders expressed skepticism about the Alcohol Act: "The Alcohol Act as it is now is far too strict, both for customers and for people who work in the bar trade. It seems almost as though going out to town should be forbidden" (Jack, 27). The interviewees gave several examples of how the Act is too rigid and said that it is impossible to follow the Act when "everyone in the place is drunk." Moreover, several of the bartenders said that they sometimes acted deliberately in breach of the Act.

Several bartenders said that the strict alcohol policy is the reason why there is so much drunkenness in nightlife: "Venues close so early, and [alcohol] is so expensive, and there are so many strict rules about what is allowed and not allowed. . . . I think that if people could decide when they want to go home and how much they drink, that there would be a more laid-back drinking culture. Not like all having to rush to drink as much as possible in the shortest possible time, and be as drunk as they can” (Anthony).

The bartenders also disputed the supervising authorities. First, they criticized the inspectors for being young and inexperienced, and having the wrong focus: "It is as though they are the ones who are responsible for whether we are allowed to be open or not. I think that shows a lack of respect for us who work in the trade" (Anna). Further, they find that the way the controls are managed by the municipality can be unprofessional: "So we find that they have got in a muddle with the reports. And it is not the first time I have heard that it has happened" (Anna). They also made fun of the inspectors and joked about how easy it was to spot them: "It's like this: 'I want a Clausthaler [a nonalcoholic beer] and I need a receipt.'. . . It's so stupid. They think that they are undercover [laughs]” (Blix).

In sum, bartenders were skeptical about both the Alcohol Act and the supervising authorities. Bartenders said that the legislation was too strict-so strict that it was impossible to follow the rules. They also criticized the control system, and they pointed to the strict rules to explain the high level of intoxication. Opposition to the Act naturally leads to resistance against law enforcement. Bartenders believe the inspectors have a low skill level, and they talk about them in a condescending manner. Such opinions about the law and the authorities may increase over-serving.

\section{Discussion}

Bartenders' interactions with customers were influenced by a stressful work situation, the cultural context for serving alcohol, and skepticism about the Alcohol Act. They pointed out that their working conditions were not suitable for responsible serving. Observations showed that the situation around the counter was sometimes so chaotic that it seemed impossible for the bartender to assess the customers. This supports the results of Saltz (1989), who points out the need for an optimal staff-customer ratio. Rydon et al. (1996) maintain that refusal would be too time-consuming for bartenders, and that it is more effective to serve the customers. McKnight (1991) shows how refusing to serve a customer can lead to conflict, which is what bartenders wish to avoid. Stockwell (1992) maintains that pseudo-patrons are often served because they do not create problems or annoy other customers.

Stockwell (1992) claims that conflict may arise between meeting the legal requirements for service of alcohol and the culture that exists at the premises. The bar should be attractive and pleasant, and the staff obliging. Our observations revealed that the pseudo-patrons were served when there were few customers in the bar, with good lighting and low music. The time and the level of intoxication of the other customers had little influence on whether they were served (Buvik \& Baklien, 2012). The bartender's job is to serve customers, and in the course of an evening at work, this happens continuously. It may be 
that this action becomes habitual; they act according to pure routine (Jager, 2003).

The serving happens within a culture characterized by liberal norms for intoxication. The bartenders are influenced by a drinking culture in which drunkenness is accepted, and this social context influences the interaction between the participants. Several studies show that employees in the hospitality industry have high alcohol consumption (Conway \& MacNeela, 2012; Norström, Sundin, Müller, \& Leifman, 2012). Conway and MacNeela (2012) explain this high consumption as the result of high stress levels, easy access to alcohol, and liberal norms that encourage excessive consumption. A U.S. study (Reiling \& Nusbaumer, 2006) shows that bartenders who have high alcohol consumption and often get drunk are more likely to serve intoxicated people. Like the bar patrons, staff behind the counter are relatively young. Participation in a social environment where both work life and leisure time are characterized by heavy drinking normalizes high levels of intoxication, which may influence over-serving.

The interviews show that the bartenders regard the Alcohol Act as too strict; over-serving may sometimes even be interpreted as a form of resistance against the law. Moreover, because of their skepticism about and criticism of the Act and inspectors, they may regard breaches of the law as justified; the shortcomings of the Act may become a legitimizing explanation (Järvinen, 2005) for serving drunken patrons. Criticism of the law and of supervising authorities makes it possible for bartenders to replace the law with their own norms, rooted in a liberal drinking culture. The law that they consider far too strict may be regarded as "accounts" or justification in the bartenders' explanations. According to Scott and Lyman (1968), one can find such legitimizing explanations when a person's actions are regarded as unacceptable.

Goffman (1961) uses the term secondary adjustments for actions that demonstrate opposition to institutional rules but are still adapted to a regulated practice, implying a form of acceptance. Viewed this way, the bartenders' over-serving may be regarded as an adaptation allowing them to maintain a feeling of autonomy (Goffman, 1961). They perceive that they have the best knowledge of the situation in their premises; therefore, they can define their own rules, which are not always in accordance with the legislation. It can also be as simple as this: breaking a law is easier if you do not agree with it.

This study shows that bartenders did not react to the intoxication of the pseudo-patrons. In this context where intoxication is normal, refusal to serve a customer is a breach of the norm.

In many countries, the on-premise sale of alcohol is typically regulated by laws and licensing systems aimed at preventing sales to intoxicated customers (Babor et al., 2010). Despite such regulations, over-serving and related harms are frequently observed (Graham \& Homel, 2008). Thus, knowledge about why bartenders serve clearly intoxicated customers is useful in the prevention of over- serving. In training bartenders, it is important to focus not only on where the limit for intoxication is, but also on how they should refuse intoxicated guests. Other strategies that licensees might use to help bartenders comply with the law include ensuring that all staff know the law and convey the clear message that serving intoxicated customers is unacceptable; providing working conditions that give bartenders a more realistic chance to serve alcohol responsibly; and providing adequate staff and management support for refusal of service when appropriate. Local authorities could support these efforts by providing more effective controls and sanctioning of the licensees' responsibilities and serving practices.

\section{Acknowledgments}

I would like to thank Bergljot Baklien, Sveinung Sandberg and Janne Scheffels for giving valuable and insightful comments, together with my colleagues in the Alcohol Research Unit at SIRUS. I would also like to thank the editor and the two anonymous reviewers at IJADR for their contributions to this article.

\section{References:}

Andreasson, S., Lindewald, B., \& Rehnman, C. (2000). Over-serving patrons in licensed premises in Stockholm. Addiction, 95, 359-363.

Babor, T. F., Caetano, R., Casswell, S., Edwards, G., Giesbrecht, N., Graham, K., . . . Rossow, I. (2010). Alcohol: no ordinary commodity: research and public policy (2nd ed.). Oxford: Oxford University Press.

Buvik, K., \& Baklien, B. (2006). Skal det være noe mer før vi stenger? Evaluering av Ansvarlig Vertskap i Trondheim. (SIRUS-rapport 4/2006). Oslo: Statens institutt for rusmiddelforskning.

Buvik, K., \& Baklien, B. (2012). Fri flyt. Bartenderes møte med berusede gjester. (SIRUS-rapport 1/2012). Oslo: Statens institutt for rusmiddelforskning.

Conway, T., \& MacNeela, P. (2012). A young person's game: Immersion and distancing in bar work. Psychology \& Health, 27, 971-989. doi: 10.1080/08870446.2011.637560

Corbin, J., \& Strauss, A. (2008). Basics of qualitative research : Techniques and procedures for developing grounded theory. Los Angeles, CA, United States: SAGE Publications.

Freisthler, B., Grunenwald, P. J., Treno, A. J., \& Lee, J. (2003). Evaluating alcohol access and the alcohol environment in neighborhood areas. Alcoholism: Clinical and Experimental Research, 27, 477-484.

Gliksman, L., McKenzie, D., Single, E., Douglas, R., Brunet, S., \& Moffatt, K. (1993). The role of alcohol providers in prevention: An evaluation of a server intervention programme. Addiction, 88, 1195-1203.

Goffman, E. (1961). Asylums: Essays on the social situation of mental patients and other inmates. New York, NY, United States: Anchor Books. 
Graham, K. (2008). [Commentary] Fiddling While Rome Burns? Balancing Rigour With The Need For Practical Knowledge. Addiction, 103, 414-415.

Graham, K., Bernards, S., Osgood, D. W., \& Wells, S. (2006). Bad nights or bad bars? Multi-level analysis of environmental predictors of aggression in late-night large-capacity bars and clubs. Addiction, 101, 15691580. doi: 10.1111/j.1360-0443.2006.01608.x

Graham, K., \& Homel, R. (2008). Raising the bar: Preventing aggression in and around bars, pubs and clubs. Cullompton, United Kingdom: Willan Publishing.

Holth, P., \& Bye, E. K. (2004). Evaluering av Ansvarlig vertskap i Bergen 2000-2003 (SIRUS-rapport 1/2004). Oslo, Norway: Statens institutt for rusmiddelforskning.

Horverak, Ø., \& Bye, E. K. (2007). Det norske drikkemønsteret (SIRUS-rapport 2/2007). Oslo, Norway: Statens institutt for rusmiddelforskning.

Hughes, K., Quigg, Z., Bellis, M., Calafat, A., Hasselt, N. v., Kosir, M., . . . Juan, M. (2012). Drunk and disorganised: Relationships between bar characteristics and customer intoxication in European drinking environments. International Journal of Environmental Research and Public Health, 9, 40684082.

Jager, W. (2003). Breaking "bad habits": A dynamical perspective on habit formation and change. In L. Hendrickx, W. Jager, \& L. Steg, L. (Eds.), Human decision making and environmental perception. Understanding and assisting human decision making in real-life settings. Groningen, Netherlands: University of Groningen:

Järvinen, M. (2005). Interview i en interaksjonistisk begrepsramme. Kvalitative metoder $i$ et interaktionistisk perspektiv: interview, observationer og dokumenter. København: Reitzel.

Kvale, S., \& Brinkmann, S. (2009). Interviews. Learning the Craft of Qualitative Research Interviewing. California, CA, United States: SAGE Publications, Inc.

Lang, E., Stockwell, T., Rydon, P., \& Beel, A. (1998). Can training bar staff in responsible serving practices reduce alcohol-related harm? Drug and Alcohol Review, 17, 39.

Lauritzen, H. C., \& Baklien, B. (2007). Overskjenking $i$ Bergen: en oppfølgingsevaluering av Ansvarlig vertskap i Bergen (SIRUS-rapport 5/2007). Oslo, Norway: Statens institutt for rusmiddelforskning.

Lund, I. (2007). Drinking on the premises in Norway: Young adults' use of public drinking places. Addictive Behaviors, 32, 2737-2746.

McKnight, A. J. (1991). Factors influencing the effectiveness of server-intervention education. Journal of Studies on Alcohol, 52, 389-397.

Nordlund, S. (1990). Drikkevaner og restaurantbruk $i$ Trondheim (SIFA-rapport 2/1990) (Vol. 2/90). Oslo, Norway: Statens institutt for alkohol- og narkotikaforskning.

Nordlund, S., \& Østhus, S. (2012). What is alcohol abuse? Attitudes to drinking in seven European countries.
Addiction Research and Theory, Early Online. doi: 10.3109/16066359.2012.732630

Norström, T., Sundin, E., Müller, D., \& Leifman, H. (2012). Hazardous drinking among restaurant workers. Scandinavian Journal of Public Health, 40, 591-595.

Oslo kommune. (2012). http://www.naringsetaten.oslo .kommune.no/

Patton, M. Q. (1990). Qualitative Evaluation and Research Methods. Newbury Park, CA, United States: SAGE.

Reiling, D. M., \& Nusbaumer, M. R. (2006). When problem servers pour in problematic places: Alcoholic beverage servers' willingness to serve patrons beyond intoxication. Substance Use \& Misuse, 41, 653-668.

Rossow, I., \& Baklien, B. (2010). Effectiveness of responsible beverage service: The Norwegian experiences. Contemporary Drug Problems, 37, 91107.

Rossow, I., \& Træen, B. (1995). På kafe i Norge: Om kafebruk, alkoholbruk og livsstil (SIFA-rapport 2/1995). Oslo, Norway: Statens institutt for alkoholog narkotikaforskning.

Rydon, P., Stockwell, T., Lang, E., \& Beel, A. (1996). Pseudo-drunk-patron evaluation of bar-staff compliance with Western Australian liquor law. Australian \& New Zealand Journal of Public Health, 20, 290-295.

Saltz, R. (1989). Research needs and opportunities in server intervention programs. Health Education Quarterly, 16, 429-438.

Scott, M. B., \& Lyman, S. M. (1968). Accounts. American Sociological Review, 33, 46-62.

Silverman, D. (2010). Doing qualitative research (3rd ed.). London, United Kingdom: SAGE.

Stockwell, T. (1992). On pseudo-patrons and pseudotraining for bar staff. British Journal of Addiction, 87, 677-680.

Toomey, T. L., Erickson, D. J., Lenk, K. M., Kilian, G. R., Perry, C. L., \& Wagenaar, A. C. (2008). A randomized trial to evaluate a management training program to prevent illegal alcohol sales. Addiction, 103, 405-413.

Toomey, T. L., Wagenaar, A. C., Erickson, D. J., Fletcher, L., Patrek, W., \& Lenk, K. M. (2004). Illegal alcohol sales to obviously intoxicated patrons at licensed establishments. Alcoholism: Clinical and Experimental Research, 28, 769-774.

Toomey, T. L., Wagenaar, A. C., Kilian, G., Fitch, O., Rothstein, C., \& Fletcher, L. (1999). Alcohol sales to pseudo-intoxicated bar patrons. Public Health Reports, 114, 337-342.

Wallin, E., Gripenberg, J., \& Andreasson, S. (2005). Overserving at licensed premises in Stockholm: Effects of a community action program. Journal of Studies on Alcohol, 66, 806-814.

Warpenius, K., Holmila, M., \& Mustonen, H. (2010). Effects of a community intervention to reduce the serving of alcohol to intoxicated patrons. Addiction, 105, 1032-1040. 